\title{
АРХЕОЛОГИЯ
}

УДК 902.26

ББК 63.4

\section{Определение географических координат археологических объектов с помощью старых карт}

\author{
С.Б. Болелов ${ }^{1}$ Г.Ю. Колганова ${ }^{2}$, М.Г. Никифоров ${ }^{3}$, Г. П. Семикопенко \\ ${ }^{1}$ Государственный музей искусства народов Востока (Москва, Россия) \\ ${ }^{2}$ Институт востоковедения РАН (Москва, Россия) \\ ${ }^{3}$ Московский государственный лингвистический университет (Москва, Россия)
}

\section{Determining the Geographical Coordinates of Archaeological Sites by Using Old Maps}

\author{
S.B. Bolelov', G.Yu. Kolganova ${ }^{2}$, M.G. Nickiforov ${ }^{3}$, G.P. Semikopenko ${ }^{3}$ \\ ${ }^{1}$ State Museum of Oriental Art (Moscow, Russia) \\ ${ }^{2}$ Institute of Oriental Studies RAS (Moscow, Russia) \\ ${ }^{3}$ Moscow State Linguistic University (Moscow, Russia)
}

Задача точного определения координат археологических объектов возникает в процессе анализа освоения территорий населением в разные исторические периоды. Наиболее близкие к действительности карты позволят получить более точные результаты. В настоящее время эта задача ставится в общем виде при построении геоинформационных систем (ГИС) отдельных памятников, комплексов памятников или обширных территорий. До этого перед археологами в принципе не стояла задача составления ГИС и высокоточного определения координат исследуемых объектов. При решении данной задачи основной проблемой является отсутствие информации по географическим координатам объектов, что критично в том случае, если самого объекта уже не существует. В качестве примера можно привести территорию исторического Хорезма, многие памятники которого были потеряны в результате сельскохозяйственного освоения земель.

Чтобы получить координаты не существующих в настоящее время памятников, можно воспользоваться спутниковыми снимками конца 1960-х - 1970-х гг., однако исследуемый объект должен быть хорошо заметен из космоса. При плохой сохранности памятника единственной возможностью для определения его географических координат является использование археологических карт, например, составленных Хорезмской экспедицией.
The problem of high precision determining the coordinates of archaeological monuments arises in the process of analyzing the development of territories by the population in different historical periods. Maps that have more exact position of the objects provide results that are more accurate. Currently, this task is posed in general terms when constructing geographic information systems (GIS) of individual monuments, complexes of monuments or separate territories. Prior to this, archaeologists, in principle, did not have the task of compiling GIS and high-precision determination of coordinates. In solving this task, the main problem is the lack of information on the geographical coordinates of the objects, which is critical if the object itself does not exist in our time. An example is the territory of historical Khorezm, many of whose monuments were lost because of agricultural land development.

It is possible to get the coordinates of the absent monuments by using satellite images of the late 1960-1970s; however, the object under study should be clearly visible from space. If the monument is poorly preserved, the only way to determine its geographical coordinates is to use archaeological maps drawn up, for example, by the Khorezm expedition.

The main idea is that if we determine the local coordinates of monuments that do not exist in our time relative to the monuments that have preserved to our

* Работа выполнена при поддержке гранта РФФИ № 19-09-00040 А. 
Основная идея состоит в том, что если определить локальные координаты не существующих в наше время памятников относительно сохранившихся до нашего времени памятников (назовем их опорными объектами), то, зная современные географические координаты опорных объектов, можно найти координаты несуществующих объектов. Точность нахождения координат определяется точностью, с которой составлены археологические карты. Поэтому возникает задача определения географических координат памятников с максимально возможной точностью с помощью археологической карты.

Ключевые слова: археологические памятники, определение географических координат, математическая обработка карт.

\section{DOI 10.14258/izvasu(2019)5-16}

\section{Старые карты и оценка их точности}

Рассмотрим задачу изучения точности карт археологических памятников на примере Правобережного Хорезма, поскольку эта территория изучена наиболее полно. При первом же рассмотрении оказывается, что большая часть опубликованных планов и схем относится к отдельным памятникам или компактным группам памятников, которые представляют собой единый комплекс [1, рис. 366]. Карты, описывающие большие территории, обычно представлены в мелком масштабе [2, рис. 2, 7], что не позволяет определить координаты отдельных объектов с приемлемой точностью для составления ГИС. Более детальные карты обычно сделаны схематично, на них обозначены только самые крупные памятники [1, рис. 29]. Аналогичная ситуация характерна и для карт Левобережного Хорезма $[3$, рис. 7,8$]$ и Южного Хорезма [4, рис. 2].

Подходящих по масштабу карт, которые пригодны для проведения анализа, оказывается совсем немного. Самые первые карты принадлежат С.П. Толстову [5, вкладки] и относятся к комплексам Кават-кала и Беркут-кала. На первом плане изображена крепость Кават-кала вместе с окружающими постройками и четырьмя фортификационными сооружениями, пронумерованными римскими цифрами I-IV. Карта описывает территорию размером 2 км на 5 км, единственным опорным объектом, пригодным для привязки координат, является сама крепость Кават-кала. Тот факт, что на плане присутствует единственный опорный объект, не позволяет проверить правильность масштаба и точность ориентации по линии меридиана. На схеме Беркуткалинского оазиса показаны несколько десятков археологических памятников, среди которых есть четыре опорных объекта: Кумбаскан-кала, Тешик-кала, Беркут-кала и замок №60. time (we shall call them reference objects), then knowing the modern geographical coordinates of reference objects, we can find the coordinates of non-existing objects. The precision of evaluation of the coordinates is determined by accuracy of the compiled archaeological maps. Therefore, the problem arises of determining the geographical coordinates of the monuments with the greatest possible accuracy using archaeological maps.

Key words: archaeological sites, determination of geographical coordinates, mathematical processing of maps.

В работе Б.В. Андрианова [6] в качестве вкладок присутствуют две подробные карты, одна из которых описывает памятники канала Гавхорэ, начиная от Джильдык-калы и заканчивая Топрак-калой и Кызыл-калой, а другая - окрестности Базар-калы.

Наконец, в работах Е.Е. Неразик приведены карты Беркут-калинского [7, рис. 1] и Якке-Парсанского [8, рис. 14] оазисов. Карта Беркут-калинского оазиса именуется в работе "картой-схемой», а ее составителем заявлен Б.В. Андрианов. Такое название вызывает некоторые вопросы, поскольку обычно термин «карта» подразумевает точные измерения в рамках погрешности, а под «схемой» понимается нечто приблизительное. На карте-схеме Беркуткалинского оазиса обозначено несколько десятков памятников, начиная от Большого Гульдурсуна в южной части и заканчивая окрестностями Большой Кыркыз-калы в северной части. Вторая карта охватывает территорию Якке-Парсанского канала от замка Большой Гульдурсун в южной части до комплекса Аязов на севере. Кроме того, на ней присутствуют некоторые памятники канала Гавхорэ, включая Джильдык и Кават-калу, что обеспечивает частичное перекрытие с картой канала Гавхорэ, составленной Б.В. Андриановым.

Таким образом, имеющиеся карты и карты-схемы покрывают территорию Правобережного Хорезма лишь частично. С другими территориями (например, с памятниками Левобережного и Южного Хорезма) ситуация еще более сложная. Все, что есть в нашем распоряжении, - это или планы отдельных памятников, которые невозможно привязать к географическим координатам, если этот объект не сохранился до нашего времени, или карты мелкого масштаба.

С целью проведения первичной проверки мы использовали карту Якке-Парсанского оазиса, опубликованную в работе Е.Е. Неразик [8]. Для эксперимен- 
та мы взяли три относительно близких друг к другу памятника, которые сохранились до нашего времени: Айр-кала, Кават-кала и Якке-Парсан. В качестве опорных объектов мы выбрали Айр-калу и ЯккеПарсан, а в качестве объекта, координаты которого нужно определить, - Кават-калу. Зная истинные координаты Кават-калы и сравнивая их с вычисленными, мы выявили ошибки координат.

Метод триангуляции, основанный на построении подобного треугольника, дает ошибку 1900 м, что довольно много. Однако это еще не самый плохой результат, поскольку угол при вершине с Кават-калой составляет около 40 градусов. В большинстве же случаев метод триангуляции плохо применим в оазисах, где памятники сгруппированы узкой полосой вдоль канала, который вытянут на десятки километров. В результате этого часто происходит ситуация, когда искомый памятник находится в вершине острого угла, градусная мера которого меньше 10-15 градусов, что приводит к большим ошибкам. Например, если в рассмотренном выше примере заменить Айркалу на Аяз-3, то ошибка локализации Кават-калы составит около $3100 \mathrm{M}$.

Другой вариант определения координат памятника заключается в отсчете расстояния по известному азимуту от выбранного опорного объекта. Азимут аналогичным образом находят из плана, а расстояние определяют, зная масштаб карты. При отсчете от Айр-калы ошибка локализации Кават-калы составит 160 м, при отсчете от Якке-Парсана - 1300 м, а при отсчете от Аяз-калы-3 она составит 2950 м.

В четырех из пяти случаев ошибка локализации памятника превышает 1 км, что считается неудовлет- ворительным результатом. Понятно, что нет смысла оценивать положение памятника по таким далеким объектам, как Аяз-кала-3, когда есть более близкие ориентиры в виде Айр-калы и Якке-Парсана. Поэтому оценка погрешности в 2-3 км является слишком пессимистичной. В то же время погрешность в 160 м, полученная при отсчете расстояния от Айр-калы, является удачным попаданием в пределы возможной ошибки более 1 км. Таким образом, точность локализации памятников по карте Беркуткалинского оазиса является неудовлетворительной.

\section{Математическая обработка старых карт}

Проведенная простейшая проверка показала, что даже крупномасштабные карты археологических памятников мало пригодны для точного определения географических координат обозначенных на них объектов. Вероятно, что перед их составителями просто не стояла задача получения точных топографических планов, а та картина, которую мы наблюдаем, вызвана сложением различных видов ошибок. К этим ошибкам можно отнести неправильный масштаб карты, неточное определение линии меридиана $^{* *}$ и погрешности, вызванные ошибочной локализацией памятников относительно друг друга.

C помощью инструментов программы Google Earth (GE) можно частично уменьшить эти ошибки, перемасштабируя археологические карты. Для этого возьмем как можно больше опорных памятников, присутствующих на плане, и измерим расстояния между ними в пикселях, а затем с помощью инструментов программы GE и в метрах.

Расстояния между памятниками

Таблица 1

\begin{tabular}{|l|c|c|c|c|c|}
\hline \multicolumn{1}{|c|}{ Памятник } & Айр-кала & Аяз-2 & Аяз-3 & Кават-кала & Якке-Парсан \\
\hline Айр-кала & - & 17645 & 17100 & 6670 & 7760 \\
\hline Аяз-2 & 1641 & - & 676 & 19870 & 10010 \\
\hline Аяз-3 & 1598 & 66 & - & 19490 & 9420 \\
\hline Кават-кала & 600 & 1816 & 1788 & - & 11575 \\
\hline Якке-Парсан & 761 & 885 & 833 & 1047 & - \\
\hline
\end{tabular}

Примечание: Выше главной диагонали - расстояния, выраженные в метрах, взятые из программы GE, ниже - pacстояния в пикселях, найденные по карте Е.Е. Неразик 2013 г.

Для уточнения истинного масштаба карты воспользуемся данными таблицы 1 , для чего разделим измеренное с помощью GE расстояние между памятниками на расстояние, выраженное в пикселях, по карте Якке-Парсанского оазиса. Числа, получен- ные в результате деления, являются масштабом карты Е.Е. Неразик, определенным по парам памятников. Усреднив все значения, получим истинный масштаб карты.

\footnotetext{
** Практика показывает, что на археологическом плане может быть обозначен как магнитный север, так и истинный север, без каких-либо пояснений в тексте. Более того, в ряде случаев магнитный север может быть неправильно пересчитан на истинный (подробнее см.: [9, с. 25-27]). В отдельных случаях можно доказать факт использования магнитного склонения с неправильным знаком (подробнее см.: [10, с. 23; 11, с.182]).
} 
Определение масштаба карты

\begin{tabular}{|l|c|c|c|c|c|}
\hline \multicolumn{1}{|c|}{ Памятник } & Айр-кала & Аяз-2 & Аяз-3 & Кават-кала & Якке-Парсан \\
\hline Айр-кала & - & 10.75 & 11.04 & 11.12 & 10.20 \\
\hline Аяз-2 & & - & 10.24 & 10.94 & 11.31 \\
\hline Аяз-3 & & & - & 10.90 & 11.31 \\
\hline Кават-кала & & & & - & 11.06 \\
\hline Якке-Парсан & & & & & - \\
\hline
\end{tabular}

Среднее значение масштаба по данным таблицы 2 составляет $M=10.89 \pm 0.15$ м в пикселе. Согласно масштабной линейке, изображенной на карте оазиса, двухкилометровый отрезок содержит 180 пикселей, что соответствует масштабу $M=11.11$ м в пикселе. Таким образом, использование неправильного масштаба приводит к систематическому завышению оценки расстояния между памятниками, причем величина ошибки линейно возрастает с увеличением расстояния до опорного объекта. Используя новый масштаб, пересчитаем расстояния между всеми парами памятников и запишем их в таблице 3 ниже главной диагонали. Выше главной диагонали находятся расстояния, измеренные с помощью программы GE.

Измеренные и вычисленные расстояния между памятниками

Таблица 3

\begin{tabular}{|l|c|c|c|c|c|}
\hline \multicolumn{1}{|c|}{ Памятник } & Айр-кала & Аяз-2 & Аяз-3 & Кават-кала & Якке-Парсан \\
\hline Айр-кала & - & 17645 & 17100 & 6670 & 7760 \\
\hline Аяз-2 & 17870 & - & 676 & 19870 & 10010 \\
\hline Аяз-3 & 17402 & 719 & - & 19490 & 9420 \\
\hline Кават-кала & 6534 & 19776 & 19471 & - & 11575 \\
\hline Якке-Парсан & 8287 & 9638 & 9071 & 11402 & - \\
\hline
\end{tabular}

Примечание: Выше главной диагонали - расстояния, взятые из программы GE, ниже - расстояния, вычисленные по карте после процедуры перемасштабирования. Все результаты приведены в метрах.

Попарно вычитая из измеренного расстояния (выше главной диагонали) вычисленное расстояние (ниже главной диагонали), получим ошибку карты. Например, согласно GE, расстояние от Айр-калы до Аяз-калы-2 составляет 17645 м, а то же самое расстояние, найденное из перемасштабированной карты Якке-Парсанского оазиса, составляет 17870 м. Разность этих значений равна -225 м, где знак «минус» означает, что карта дает завышенное расстояние. Проведя эту процедуру по всем парам памятников, получим набор ошибок расстояний.

Таблица 4

Набор ошибок расстояний между памятниками Якке-Парсанского оазиса

\begin{tabular}{|l|c|c|c|c|c|}
\hline \multicolumn{1}{|c|}{ Памятник } & Айр-кала & Аяз-2 & Аяз-3 & Кават-кала & Якке-Парсан \\
\hline Айр-кала & - & -225 & -302 & 136 & -527 \\
\hline Аяз-2 & & - & -43 & 94 & 372 \\
\hline Аяз-3 & & & - & 19 & 349 \\
\hline Кават-кала & & & & - & 173 \\
\hline Якке-Парсан & & & & & - \\
\hline
\end{tabular}

Среднее значение ошибки, определенное по 10 измерениям, составляет $\Delta R=-5 \pm 287$, следовательно, с помощью данной карты пространственная локализация памятника может быть определена с точностью до 300 м в пределах одного стандартного отклонения.
Применяя аналогичную методику к карте Беркуткалинского оазиса Е.Е. Неразик 1966 г., получим среднее значение ошибки $\Delta R=-52 \pm 196$, что дает точность 200 м в пределах одного среднеквадратичного отклонения (СКО, табл. 5).

Набор ошибок расстояний между памятниками Беркут-калинского оазиса

Таблица 5

\begin{tabular}{|l|c|c|c|c|c|c|}
\hline \multicolumn{1}{|c|}{ Памятник } & Атсыз-кала & Беркут & Зам. №60 & Кумбаскан & Тешик-кала & Уй-кала \\
\hline Атсыз-кала & - & -316 & -370 & -173 & -282 & -324 \\
\hline Беркут-кала & & - & 90 & 170 & -21 & -66 \\
\hline Замок №60 & & & - & 210 & 154 & 5 \\
\hline Кумбаскан & & & & - & 129 & 42 \\
\hline Тешик-кала & & & & & & - \\
\hline Уй-кала & & & & & & - \\
\hline
\end{tabular}


Худшую точность имеет карта Беркут-калинского оазиса С.П. Толстова 1948 г. Значение ошибки составляет $\Delta R=28 \pm 297$, что обеспечивает точность локализации около 300 м. Данная оценка получена по четырем опорным памятникам, которым соответствуют шесть пар расстояний. Поэтому она менее надежна, чем оценки, полученные ранее.

Наконец, самую высокую точность имеет карта канала Гавхорэ, составленная Б.В. Андриановым, где погрешность пространственной локализации $\Delta R=1 \pm 90$, чему соответствует ошибка 90 м в пределах одного СКО.

\section{Точное определение координат памятника}

Приведенная выше процедура перемасштабирования старых археологических карт позволяет не только существенно снизить ошибку локализации объекта, но и получить оценку точности определения координат. Поскольку ошибка описывается распределением случайной величины, то полагая, что распределение является субнормальным, погрешность в пределах 1 СКО реализуется с вероятностью 66\%, а погрешность в 2 СКО - с вероятностью $94 \%$.

Эти рассуждения справедливы при отсчете от одного памятника. Если для нахождения координат использовать $n$ опорных объектов, то при нормальном распределении ошибки погрешность локализации уменьшится как $\sqrt{\mathrm{n}}$. Следовательно, использование четырех опорных объектов позволяет повысить точность в два раза. Приведем алгоритм определения координат искомого памятника с помощью археоло- гической карты по набору опорных объектов с известными географическими координатами.

Алгоритм определения координат.

1. Из числа присутствующих на карте объектов выберем $n$ опорных памятников, с помощью программы GE определим их географические координаты и составим матрицу M1 расстояний между ними, которая будет иметь размерность $n \times n$.

2. С помощью отсканированной археологической карты аналогичным образом составим матрицу М2 попарных расстояний между этими же памятниками. Разделив элементы матрицы метрических расстояний M1 на соответствующие элементы матрицы пиксельных расстояний М2 и усреднив результат, определим истинный масштаб карты.

3. Умножив матрицу М2 на истинный масштаб карты, получим матрицу вычисленных расстояний между памятниками М3. Вычитая из матрицы M1 матрицу M3, получим матрицу ошибок. Вычислив СКО элементов последней матрицы, получим точность карты ${ }^{* *}$.

4. Выберем памятник, географические координаты которого нужно найти и измерить в пикселях на отсканированной карте в $n$ расстояний от заданного памятника до каждого опорного объекта. Зная истинный масштаб карты, переведем пиксельные расстояния в метрические.

5. От каждого опорного объекта проведем окружность с радиусом, равным метрическому расстоянию до заданного памятника. Искомая точка будет находиться в центре пересечения окружностей (рис. 1; рис. 2).

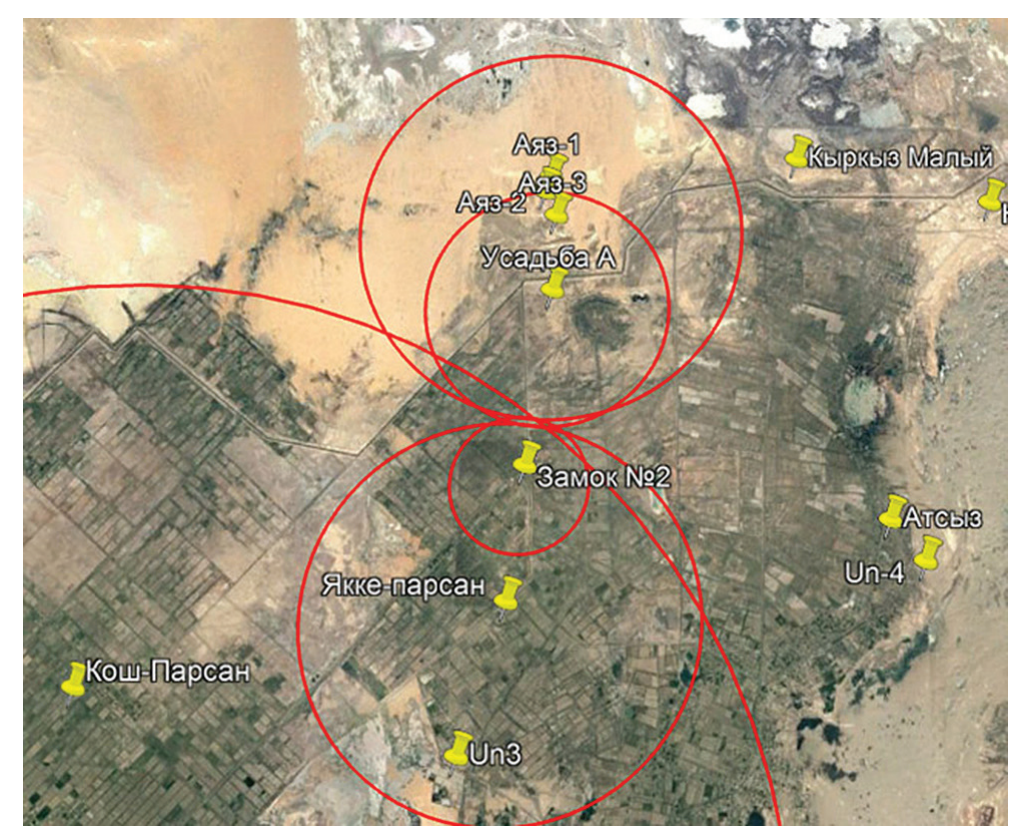

Рис. 1. Пример нахождения Хайдар-тепе геометрическим методом по карте Якке-Парсанского канала. В силу погрешностей пересечение происходит в некоторой области

\footnotetext{
*** Все упомянутые элементарные математические преобразования можно реализовать в популярных статистических пакетах, например, в Statistica.
} 


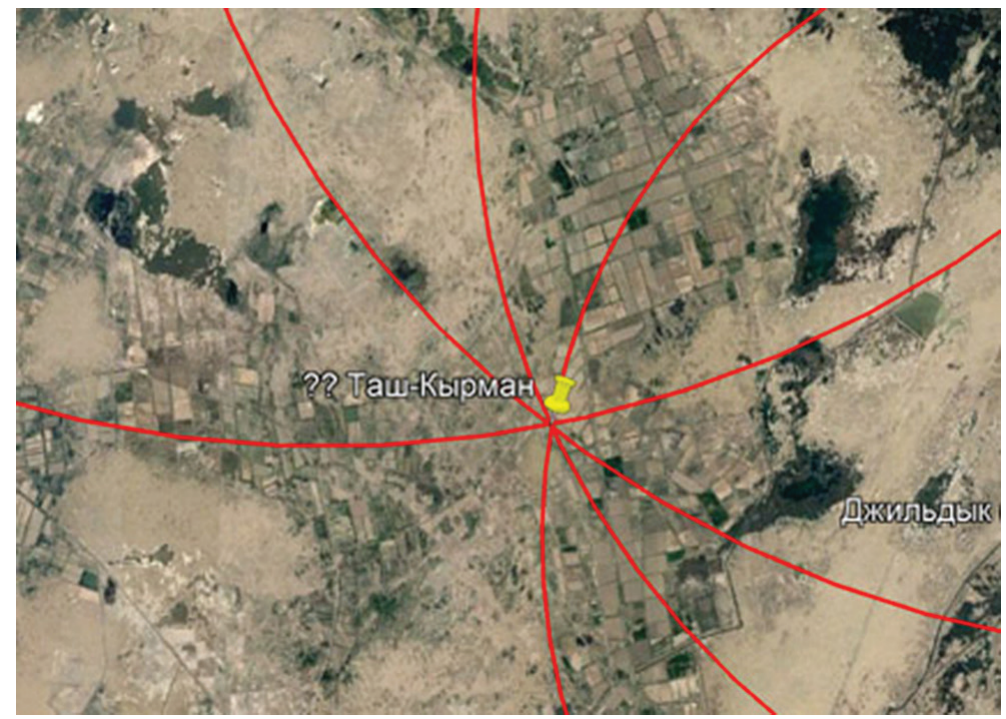

Рис. 2. Пример нахождения Таш-Кырмана геометрическим методом по карте канала Гавхорэ.

Пересечение окружностей происходит практически в точке

Преимущество геометрического метода состоит в том, что он очень нагляден и может быть легко реализован в программе GE. Тем не менее при поиске Хайдар-тепе по карте Е.Е. Неразик пересечение окружностей произошло не в точке, а в некоторой области, имеющей форму эллипса (см. рис. 1). Это является следствием ошибок, допущенных при составлении карты. В то же время при локализации Таш-Кырмана пересечение окружностей происходит практически в одной точке, что говорит о высокой точности карты.

Недостатком геометрического метода является то, что координаты искомого объекта выбираются произвольно. Если пересечение окружностей происходит вне очень малой области, размером, скажем, в 20-30 м, как получается при оценках по картам Б.В. Андрианова, то этот вопрос не актуален, однако в большинстве случаев задача требует математического решения.

Можно предложить много способов нахождения координаты искомого объекта в зависимости от модельных представлений. Например, ввести весовые коэффициенты, которые зависят от удаленности каждого опорного объекта до памятника, причем сами зависимости также могут быть определены различными способами.

Рассмотрим «простейшую» модель. Предположим, в нашем распоряжении есть только два опорных объекта, по которым необходимо вычислить координаты некоторого памятника. В соответствии с приведенным выше алгоритмом в пункте 5 мы получим три возможные ситуации: а) окружности не пересекаются; б) окружности имеют пересече- ние в одной точке; в) окружности пресекаются в двух точках. В случае варианта «а» координатами памятника будем считать координаты центра отрезка, соединяющего ближайшие точки двух окружностей. В случае «б» координаты памятника - это точка касания двух окружностей. В случае «в» нужно найти две точки пересечения и выбрать из них наиболее подходящую по координатам. Естественно, этого нельзя сделать, если в нашем распоряжении есть только два опорных памятника. Однако на практике, когда используется несколько опорных объектов, зная приблизительное положение искомого объекта, из пары возможных координат выберем наиболее близкую.

Описанную процедуру применим к каждой паре опорных объектов, в результате чего получим $n \cdot(n-1) / 2$ координат. Устраняя из этого множества выбросы на уровне 2 СКО и усредняя координаты, получим географические координаты искомого объекта.

\section{Проверка методики}

Для проверки предлагаемой методики мы взяли карту Якке-Парсанского канала, а в роли искомого объекта - Кават-калу, поскольку координаты этой крепости известны точно. В качестве опорных объектов были выбраны пять ближайших памятников: Айр-кала, Якке-Парсан, Джильдык, Кумкала и Аяз-кала-3, которые также сохранились до нашего времени. В результате отсчета расстояний от пяти опорных объектов получим 10 вариантов координат, на которых может находиться Кум-кала (табл. 6). 
Оценки координат Кават-калы с помощью «простейшей» модели.

Таблица 6

\begin{tabular}{|c|l|c|c|}
\hline № & \multicolumn{1}{|c|}{ Пара памятников } & Широта & Долгота \\
\hline 1 & Аяз-3 - Айр & 41,853481 & 60,912644 \\
\hline 2 & Аяз-3 - Джильдык & 41,848086 & 60,923775 \\
\hline 3 & Аяз-3 - Кум-кала & 41,853789 & 60,911794 \\
\hline 4 & Аяз-3 - Якке-Парсан & 41,854303 & 60,910908 \\
\hline 5 & Айр - Джильдык & 41,849975 & 60,913469 \\
\hline 6 & Айр - Кум-кала & 41,853719 & 60,912908 \\
\hline 7 & Айр - Якке-Парсан & 41,852333 & 60,913492 \\
\hline 8 & Джильдык - Якке-Парсан & 41,847953 & 60,916442 \\
\hline 9 & Джильдык - Кум-кала & 41,851325 & 60,907283 \\
\hline 10 & Кум-кала - Якке-Парсан & 41,853644 & 60,911719 \\
\hline
\end{tabular}

Чтобы найти среднее значение долготы и широты, сначала следует устранить выбросы, т.е. измерения, которые значительно отличаются от остальных.
Для этого нанесем все десять точек в координатах «долгота - широта» (рис. 3).

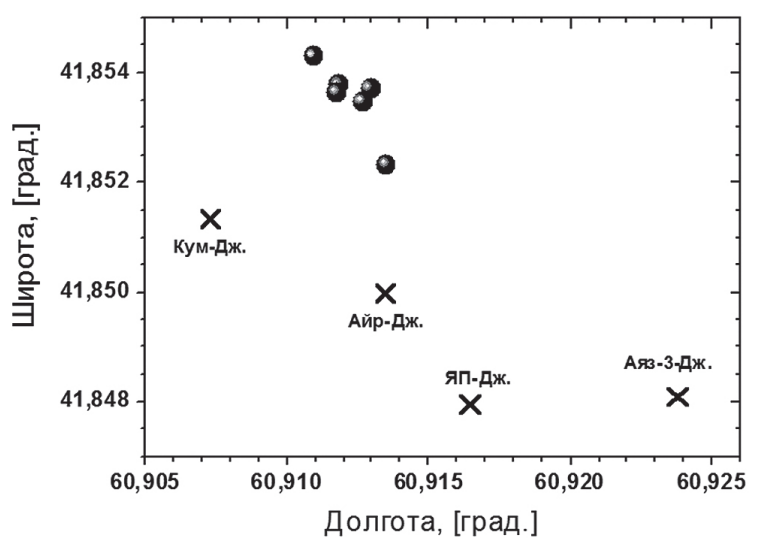

Рис. 3. Предполагаемые координаты Кават-калы по данным таблицы 6. Общая группа точек обозначена кружками. Крестиками показаны наиболее отклоняющиеся координаты

Из рисунка 3 видно, что шесть точек, отмеченные кружками, сгруппированы достаточно плотно. В то же время четыре точки, обозначенные крестиками, удалены как от основной группы, так и друг от друга. Существенно важным является то, что во всех четырех парах сильно отклоняющихся измерений, отмеченных крестиками, присутствует Джильдык. Очевидно, что локализация этого памятника на карте Е.Е. Неразик дана с гораздо большей ошибкой, чем локализация остальных памятников. Это объясняет столь значительные отклонения на рисунке 3 всех точек, на которых присутствует Джильдык. Поэтому этот памятник следует исключить из рассмотрения и определить координаты Кават-калы по оставшимся шести точкам.

В результате усреднения получим вычисленны е координаты $\phi_{\text {calc }}=41^{\text {п }} 51^{\prime} 12.76 "$ с.ш . $\lambda_{\text {calc }}=60^{\text {п }} 54^{\prime} 44.08^{\prime \prime}$ в.д . в то в ремя как GE-координаты центра памятника составляют $\phi_{\mathrm{GE}}=41^{\Pi} 51^{\prime} 14.75^{\prime \prime}$ с.ш., $\lambda_{\mathrm{GE}}=60^{\Pi} 54^{\prime} 41.10^{\prime \prime}$ в.д. Это означает, что ошибки координат составляют в широте $\Delta \phi=2 "$ и $\Delta \lambda=3 "$, чему соответствует расстояние 92 м. Поскольку геометрические размеры Кават-калы составляют $155 \times 175$ м, то вычисленные координаты попадают внутрь периметра стен памятника.

Оцененная после перемасштабирования ошибка карты Якке-Парсанского канала составила 287 м, при этом для локализации Кават-калы мы использовали $\mathrm{n}=6$ точек. Тогда теоретическая оценка по-

грешности равна $\Delta S=287 / \sqrt{6}=117$ м, что соответствует найденной ошибке локализации памятника в 92 м.

Предлагаемая нами методика может быть применена для локализации объектов на любых археологических картах. Единственное ограничение состоит в том, что на этих картах должны присутствовать видимые из космоса опорные объекты, координаты которых можно определить с высокой точностью. 


\section{Библиографический список}

1. Толстов С.П. По следам древнехорезмийской цивилизации. М. ; Л., 1948.

2. Толстов С.П. По древним дельтам Окса и Яскарта. M., 1962.

3. Калалы-гыр-2. Культовый центр в Древнем Хорезме IV-II вв. до н. э. / отв. ред. Б. И. Вайнберг. М., 2004.

4. Древности Южного Хорезма / отв. ред. М. А. Итина. М., 1991.

5. Толстов С.П. Древний Хорезм. Опыт историко-археологического исследования. М., 1948.

6. Андрианов Б. В. Древние оросительные системы Приаралья. М., 1969.

7. Неразик Е.Е. Сельские поселения афригидского Хорезма. М., 1966.
8. Неразик Е.Е. Формирование раннесредневекового общества в низовьях Амударьи. М., 2013.

9. Колганова Г.Ю., Никифоров М.Г., Рейджс В. Археоастрономические исследования древнехорезмийского комплекса Кой-Крылган-кала // Восток (Oriens). № 4. М., 2014.

10. Кой-Крылган-кала - памятник культуры древнего Хорезма IV в до н. э. - IV в н. э. // Труды Хорезмской археолого-этнографической экспедиции. Т. V / отв. ред. С. П. Толстов, Б.И. Вайнберг. М., 1967.

11. Болелов С.Б., Колганова Г.Ю., Никифоров М.Г. Элементы гармонизации в архитектуре памятника КойКрылган-кала // Краткие сообщения Института археологии. Вып. 237. М., 2015. 